\title{
GEOFILTRATION STUDIES OF CLAY AT THE FUTURE RADIOACTIVE WASTE REPOSITORY FOR IGNALINA NUCLEAR POWER PLANT
}

\author{
Petras Klizas \\ Department of Hydrogeology and Engineering Geology, Faculty of Natural Sciences, Vilnius University, \\ M. K. Čiurlionio g. 21/27, 03101 Vilnius, Lithuania
}

Submitted 20 Dec. 2012; accepted 07 Mar. 2014

\begin{abstract}
Clay geofiltration studies became important in Lithuania when the clays began to be used as geofiltration barriers for waste disposal sites/repositories. The clay is planned to be used also in construction of the future radioactive waste repository for the Ignalina Nuclear Power Plant. The results of investigation on Stabatiške subformation till clay occurring at the base of the repository are given in the paper. The investigation has been performed with the purpose to determine potential dependence of clay filtration coefficient values on the number of freeze-thaw cycles and duration of filtration. The filtration coefficient for the repository till clay has been found to be greatly varying at the start of the filtration and during the experiment that lasted several days. This confirms that, during the filtration, structural changeover of clay-forming aggregates takes place with pore space volumes changing and affecting the filtration coefficient values. The filtration parameters are even more affected by freeze-thaw cycles and their number. When the clay thaw is finished the colmatation of fissure system is very slow and incomplete.
\end{abstract}

Keywords: clay geofiltration, hydraulic conductivity, soil pollution, water contamination, freeze-thaw cycles.

\section{Introduction}

Lately the demand in geofiltration investigations on clay deposits have significantly increased in Lithuania. Being impermeable to water clay is used for constructing various barriers against percolation of hazardous waste, including radioactive ones, in repositories and landfills of various type and size. The EU laws contain strict geofiltration requirements to be applied for the clay used for such barriers. The hydroisolation capability of clay layers depends on many interrelated factors and parameters: permeability, porosity, microstructure peculiarities of pore space, moisture, thickness of natural or artificial hydroisolation, clay mineral composition, chemical composition of future leachate, hydrodynamic load, potential impact of freeze etc. However, the main indices affecting the efficiency of the future geofiltration barrier are hydraulic conductivity and clay layer thickness, which are regulated quantitatively. In France, for instance, there is a complex concept called 'passive safety barrier' (Cassan 2005). Depending on a degree of waste hazardousness, it defines the ratio between the barrier hydroisolation thickness and the hydraulic conductivity. Therefore, it is very important to have accurate values of hydraulic conductivity determined, because formation of necessary thickness of permeable layer is easier to be done. To select the type of clay satisfying percolation requirements is more difficult, because these characteristics are changing in time due to the above mentioned factors.

The percolation characteristics of Lithuanian clays are not widely studied, since there was almost no such demand. Another reason might be the fact that due to the very low percolation, experimental laboratory investigations would be long-lasting, hence, time- and fundsconsuming. Our investigations have been performed on order by a private company, therefore, the information about sampling sites, depth etc., which is not important methodologically for the present study, are not provided in this paper. We shall analyse the dependence of clay geofiltration parameters on filtration duration, its stopping and renewal, as well as number of freeze-thaw cycles.

Corresponding author: Petras Klizas

E-mail: petras.klizas@gf.vu.lt 
The abundance in scientific publications of late years shows lively interest in clay geofiltration studies in different geological regions. For one of such investigations a French expansive clay known as Fo-Ca, which is a natural Ca-smectite coming from the Paris basin of Ypersian age, was used. Permeability experiments were performed with distilled water and several copper concentrations $\left(10^{-3}\right.$ to $\left.10^{-1} \mathrm{~mol} / \mathrm{l}\right)$. The permeability of clay was found to increase with copper concentration. Using the syringe oedometer, permeability was $1.1 \mathrm{E}-12 \mathrm{~m} / \mathrm{s}$ with distilled water, and $2.4 \mathrm{E}-12 \mathrm{~m} / \mathrm{s}$ with the $0.1 \mathrm{~mol} / \mathrm{l}$ copper solution (Jullien et al. 2002). The Mont Terri rock laboratory in Switzerland studied compacted Opalinus Clay core samples from $200 \mathrm{~m}$ depth. Permeability and porosity was determined to be a function of time at constant pressure (Jobmann, Wilsnack 2010). In a few studies it was shown that composition and compression of clay are very important for its hydraulic conductivity, permeability and filtration properties (Shafiee 2008; Ebina et al. 2004; Hamdi, Srasra 2008).

In this paper we show similar functional relationships for Grūda subformation till clay from Stabatiške site in Lithuania. In another study (Heister et al. 2005), the material taken from the clay between the motorway and railroad on the northeast of the harbour in Rodbyhavn, owned by Dansk Bentonit, was examined and a new laboratory set-up for measurements of electrical, hydraulic and osmotic fluxes in clays and clay-rich materials was established. Researches performed in Italy on water vapour permeability of clay bricks showed relationships between a wide range of chemical and mineralogical compositions and particle size distributions. The correlations of vapour permeability, open and closed porosity, bulk density, mean pore diameter, pore size selection and specific surface were determined (Dondi et al. 2003). Soil air permeability is one of the most important parameters which govern the aeration in agricultural soils. The relationship between air permeability, soil capacity parameters and vertical stress was analysed by performing confined uniaxial compression tests and air permeability measurements on three different French soils (Tang et al. 2011).

Permeability studies for frozen rocks are also often performed in the regions where mean winter air temperatures are below zero (Al Houri et al. 2009; McCauley et al. 2002). In France, the permeability of non-cohesive rock mixtures of different grain-size has been studied. The laboratory tests were performed by a permeameter at varying negative temperatures and using different permeants: water, different $\mathrm{NaCl}$ solutions, bentonite and trapped decane mixture (Enssle et al. 2011). In another research performed in Canada an infiltration of snowmelt water under small depressions has been examined. These depressions stored most of the snowmelt runoff generated within their respective watersheds (Hayashi et al. 2003). In a current work we analyse rock permeability variations under the freeze and thaw impact for the first time in Lithuania. The oedometric laboratory and field infiltration studies on suitability of clay deposits from Šaltiškè, Pašaminè and Stabatiškè sites for the Ignalina nuclear power plant radioactive waste repository hydroisolation barrier were performed by using a double ring infiltrometer and injection into a borehole method after V. Nasberg (Gadeikis et al. 2012). Possibilities of transport and accumulation in soil of radionuclides and heavy metals were determined by properties of clay (Jakimavičiūtè-Maselienè et al. 2012; Pundytè et al. 2011).

The main objective of our study was to determine filtrational parameters of the clay from the future radioactive waste repository at Stabatiške site. We aimed to determine how the filtration coefficient depends on the number of freeze-thaw cycles, the colmatation after freezing and the duration of filtration. Filtration coefficient is the main parameter, which determines the spread of radioactive nuclides in rocks of aeration zone and protects the below laying groundwater from possible pollution.

\section{Composition and structure of clayey rocks}

Structural characteristics of clayey rocks are determined by dispersed clay particles called micelles. The micelles in clayey rocks are notable for an electric double layer formed at the boundary between the solid particle and the liquid (water in clay). Structural diversity of clay minerals and crystal-chemistry specificity of particle surfaces at the microstructural level change the understanding of clay pore space. These features of clay cause different percolation course, if compared to other dispersed systems composed of similar particles with no interaction, such as sand, for instance. Clay beds at the microstructural level are notable for a higher degree of diversity and depend on ratio of three basic clay minerals - kaolinite, muscovite mica and sodic montmorillonite. The macrostructural diversity of beds is caused by clastic inclusions, macropores, lamination and fracturedness in highly lithified beds. The macropores are typical of the clay beds in the aeration zone, including those artificially formed as hydroisolation barriers at the land surface. Pores and cracks are main factors determining permeability anisotropy of clay beds. A characteristic feature of such macropores is their potential clogging (colmatation) during long period, therefore, hydraulic conductivity of clay sample gradually decreases during a long-term experiment. This process was observed by us during long-term permeability testing. During percolation through clay pores ranging from 3 to $20 \AA ̊$, the following processes also take place: cation exchange, hydratation-dehydratation at the surface and inside of clay minerals and sticking of particles into larger aggregates. At the micro-aggregate level, when pores are within the 
range of $1-10 \mu \mathrm{m}$, changes in pore and structure space are observed in relatively homogenous samples and beds, and this causes anisotropicity of water percolation in clay (Oradovskaja 1983). During percolation, the structural changeover of particles takes place, and this process is more effective the more diverse is the initial structure. At larger pressure gradients, flat particles of clay minerals reorientate parallel to the water flow lines, and at lower pressure gradients they do not move back to their initial position. This effect is typical of high moisture and porosity clay and loam.

The abundance of scientific publications on various clay studies, especially on geofiltration, shows the significance of these rocks and their practical usefulness in solving environmental problems.

\section{Methods and materials studied}

The goal of the present study is to assess the variations of clay permeability properties: (1) during a long-term percolation; (2) repetition of percolation stopping and renewal cycles; (3) during sample freeze and thaw. The Grūda subformation till clay (gIIIgr) at the projected Stabatiške waste repository site has been chosen for detailed investigations. Macroelement oxides and mineralogical composition of examined clay were determined in the laboratory of Center for Physical Sciences and Technology. Average percentage of macroelement oxides in clay fraction is as follows: $\mathrm{Na}_{2} \mathrm{O}-0.7 \% ; \mathrm{MgO}-2.9 \% ; \mathrm{Al}_{2} \mathrm{O}_{3}-10.8 \%$; $\mathrm{SiO}_{2}-59.9 \% ; \mathrm{K}_{2} \mathrm{O}-3.7 \% ; \mathrm{CaO}-8.1 \% ; \mathrm{TiO}_{2}-0.5 \%$ and $\mathrm{Fe}_{2} \mathrm{O}_{3}-10.6 \%$. The average percentage of clay minerals in clay fraction and deposits (in parenthesis) is as follows: illite $-83.3(15.3) \%$, kaolinite - $15.8(2.8) \%$ and chlorite $-0.9(0.2) \%$. The following physical properties have been determined as well: natural moisture content - $12 \%$; natural density $-2.25 \mathrm{Mg} / \mathrm{m}^{3}$; hydraulic conductivity obtained by oedometric measurements at 0.1 and $0.2 \mathrm{MPa}$ load is, respectively, $2.3 \mathrm{E}-11 \mathrm{~m} / \mathrm{s}$ and $7.1 \mathrm{E}-11 \mathrm{~m} / \mathrm{s}$. The clay analysed in this study was taken from the same place as one used in publication of Gadeikis et al. (2012). Laboratory permeability testing has been performed with non-compacted clay of natural structure. A scheme of the permeameter used is given in Figure 1.

This type infiltrometer is applied for filtering performed according to a non-stationary scheme. Maximum piezometric head is up to $35 \mathrm{~cm}$, sample height is $4 \mathrm{~cm}$, cross-section area is $40 \mathrm{~cm}^{2}$; and initial of maximum hydraulic gradient is 8,75 .

Hydraulic conductivity is calculated by the formula:

$$
K=\frac{2.3 A L}{S T \log \frac{H_{1}}{H_{2}}},
$$

where: $A$ is piezometer cross-section area; $L$ is sample height; $S$ is filtration ring cross-section area; $T$ is filtering time, and $H_{1}$ and $H_{2}$ are hydraulic heads.

Starting the geofiltration investigations, first of all, we have assessed the variations in hydraulic conductivity depending on duration of filtering. Then an attempt was made to determine the filtering process during its stopping and renewal. The second cycle of experiments dealt with the impact of freezing on clay hydraulic conductivity, as well as the assessment of the role of the freeze and thaw cycles. All the filterings have been performed according to a non-stationary scheme.

Of late years, the alternation of periods with negative and positive air temperatures in Lithuania is frequently observed, therefore, it is important to assess the effect of these phenomena on clay permeability properties. The clay hydroisolation barriers formed for the near-surface waste repositories of various types are not thick. Their upper part, as a rule, freezes in winter and thaws in spring. During all the laboratory experiments, measurements of water evaporation, air temperature and humidity have been done, with the purpose to eliminate the influence of these factors on hydraulic conductivity values determined. The PV infiltrometer has an open orifice for filtrate outflow as the piezometric tubes used with open-ended

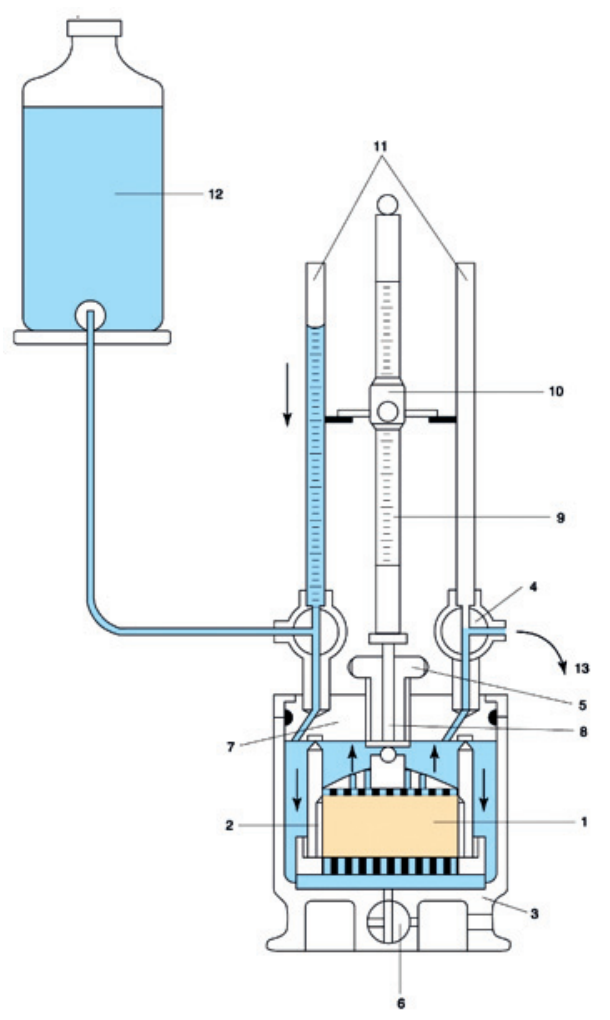

Fig. 1. A scheme of PV infiltrometer (permeameter): 1 - clay sample; 2 - filtering chamber ring; 3 - a case; 4 - three-way faucet (tap); 5 - valve; 6 - two-way faucet (tap) for filling the infiltrometer with water; 7 - a case cover; 8 - thermometer; 9 - water level scale in piezometer; 10 - sliding marker; 11 piezometers; 12 - a container for water; 13 - filtrate outflow orifice 
top. Therefore it is very important to have data on evaporation intensity, especially for long-term measurements and at very low filtrate debits at low hydrodynamic head gradients. The longest filtering lasted 430 hours, and minimum hydrodynamic head gradients reached just some tenths of a digit one. The clay sample was frozen together with a filtration chamber ring in a freezer at a stable $-7^{\circ} \mathrm{C}$ temperature for 5 days. According to the data from Utena Meteorological Station, which belongs to the network of Lithuanian Hydrometeorological Service, the average minimal temperature of January and February, in the time period from 1971 until 2000, was -7.1 and $-7.3{ }^{\circ} \mathrm{C}$ respectively (www.meteo.lt). There is no meteorological station in Visaginas, therefore Utenos Meteorological Station, which is the closest one to Visaginas, was chosen. The freezer, which was used for experiments, could be regulated with the accuracy of one degree of Celsius, thus $-7^{\circ} \mathrm{C}$ was used. By observing the freezing of the clay sample it was determined that after 5 days a stable system of cracks forms Figure $4 \mathrm{~B}$, which does not change while freezing longer.

\section{Results and analyses}

The clay sample before the first filtering was saturated with distilled water in the filtering chamber. The PV infiltrometer allows filtering by forming percolation flows from top to the bottom and vice versa (Fig. 1). For saturation, as well as all filterings, the upward flow of water has been applied. This enabled to saturate the clay sample of the initial $15 \%$ natural humidity by creating a unit hydraulic head. Water level in piezometer coincided with the top of the

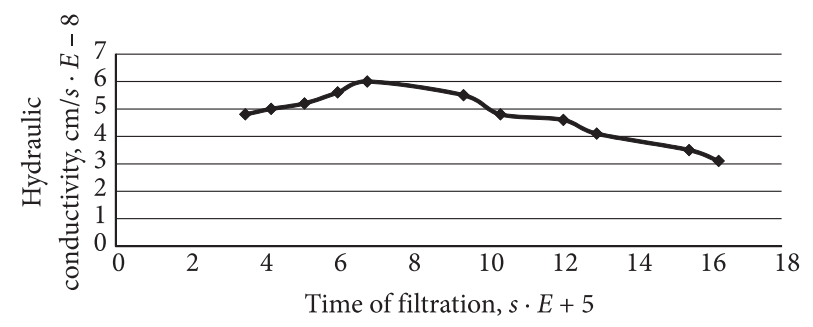

Fig. 2. Hydraulic conductivity of clay versus the filtering duration during the first filtering term



Fig. 3. Hydraulic conductivity of the same clay sample versus the filtering time at the renewal of the experiment after two weeks sample. The course of the first filtering showed the increase in hydraulic conductivity during 194 hours of filtering and the decrease in head gradient from 8.75 to 3.5 (Fig. 2). Further, the hydraulic conductivity values decreased nearly linearly as far as the stopping of filtering after 430 hours with a decrease in head gradient to 1.2 (Fig. 2).

Such a course of filtering can be explained by incomplete saturation of a sample, although the process of saturation lasted 48 hours. This is confirmed by the increase in mass of the sample from $335 \mathrm{~g}$ to $338 \mathrm{~g}$ measured after the saturation and filtering. The second part of the filtering course, i.e. the decrease in hydraulic conductivity, can be explained by changes in clay pore spaces caused by structural changeovers in clay minerals and their aggregates. The second reason of this phenomenon can be explained so: due to a decrease in head gradient with time, a lower content of bound water in clay moves together with percolating flow and turns into an immobile phase. Therefore, as the head values decrease, the filtering debit declines unproportionally, as well as the hydraulic conductivity.

After the first filtering was over, the clay sample remained in the gauge in distilled water. The second filtering was renewed after two weeks. The results obtained are presented in Figure 3. The initial stage of filtering again shows increase in conductivity values, as in the first filtering, followed by stabilisation. The difference from the first case is that there was no increase in sample mass, and a change in hydraulic conductivity appeared earlier than in the first case. This can be explained by further structural changes in clay pore spaces during the filtering. The structural changes in the clay sample being in water for two weeks confirmed the fact that after the first filtering the hydraulic conductivity value was $3.1 \mathrm{E}-8 \mathrm{~cm} / \mathrm{s}$, and it grew to $3.9 \mathrm{E}-$ $8 \mathrm{~cm} / \mathrm{s}$ at its renewal after two weeks.

Such a change of hydraulic conductivity values with time can be explained by the changes in pore spaces taking place not only during filtering, but also when the sample is swelling in water, i.e. the aggregates of clay particles changeover structurally. This conclusion is confirmed by other authors, which obtained similar results. In France, the Callovo-Oxfordian clay formations consisting of the muscovite mica (Comptoir de Mineraux et Matieres premieres) are essentially composed of $\mathrm{SiO}_{2}$ and sodium montmorillonite in bentonite (Oene, France). The analysis of this by Scattering Electron Microscopy showed that the structure of pore space changed if compared low humidity samples to those after swelling $24 \mathrm{~h}$ in water (Mammar et al. 2001). After the second filtering was stopped, the clay sample was taken out from the infiltrometer together with the filtering chamber ring and placed into a freezer with constant temperature $7{ }^{\circ} \mathrm{C}$ below freezing point. After 5 days, the sample was taken out. The picture of the sample after the freezing is given in Figure 4, where freeze cracks are well seen. 




A

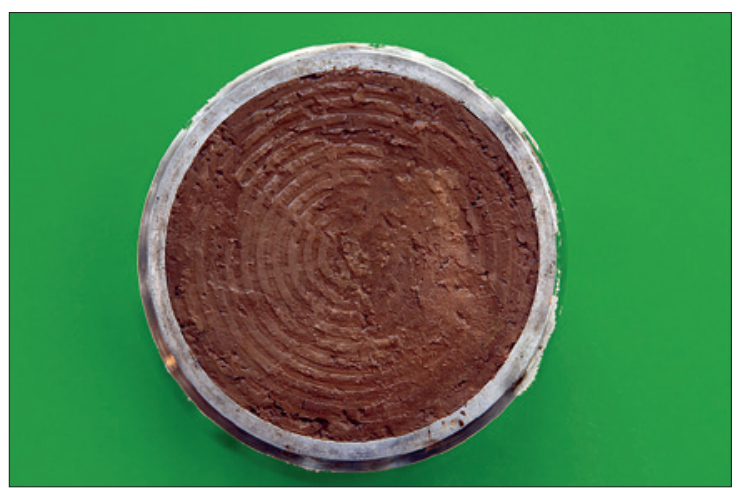

C

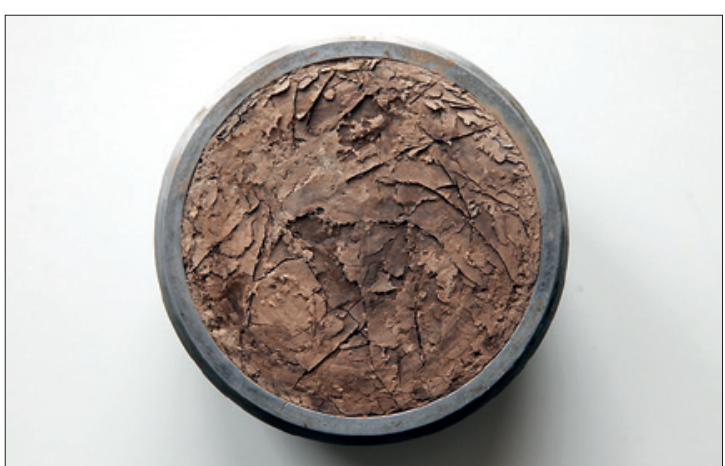

B

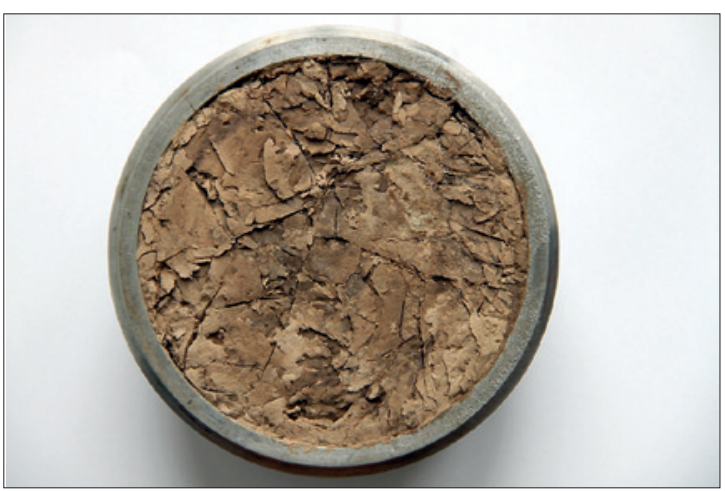

$\mathrm{D}$

Fig. 4. Picture of the sample with the filtering chamber ring: A - after first freezing; B - after second freezing; $\mathrm{C}$ - after second filtration; D - after third freezing

Weighing the sample after the freeze showed a decrease in its mass by $2 \mathrm{~g}$. This confirms that, during freezing, water partly migrates from the sample towards the freeze zone at the walls of the freezer. The frozen sample was put outright into the infiltrometer to begin filtering. The initial results of this filtering are given in Figure 5. The data obtained show the course of thawing at the start of the filtering, i.e. cyclic acceleration and deceleration. The hydraulic conductivity values obtained ranged from $5 \mathrm{E}-6 \mathrm{~cm} / \mathrm{s}$ to $3.5 \mathrm{E}-5 \mathrm{sm} / \mathrm{s}$, thus, being higher by two orders of magnitude than before the freezing.

After the renewal of filtering of completely thawed sample, as fixed according to water temperature course in filtering chamber, the changes in hydraulic conductivity are presented in Fig. 6. The filtering course shows a rather intense deceleration of percolation and stabilisation of hydraulic conductivity. This reveals a strong effect of cracks formed during freezing and rather rapid colmatation of the freeze crack system.

As the filtering after the first freezing is over, the sample was frozen once more under the identical temperature regime. A picture of the sample after the second freezing shows even more obvious freeze cracks, although the crack system looks alike as after the first freezing (Fig. 7). This indicates that the cracks clogged during filtering opened again and got wider and sharper. The filtering course is very similar, but the stabilisation goes much slower and

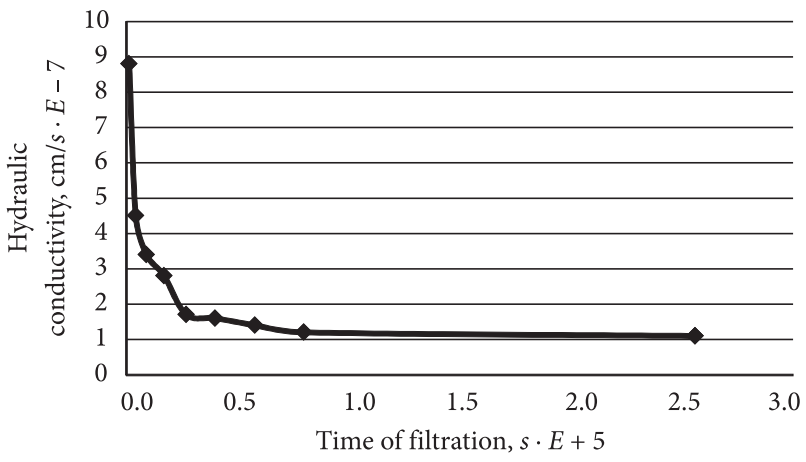

Fig. 5. Variations of clay hydraulic conductivity in time when the filtering and the thawing takes place at the same time in filtering chamber



Fig. 6. Variations of clay hydraulic conductivity during the initial filtering performed after thawing of the sample 
longer, thus confirming the conclusion that the cracks are wider, therefore, hydraulic conductivity values are higher.

The course of filtering after the stopping and renewal is identical to that before the freezing as the results given in Figure 8 indicate.

As the second filtering was completed, the sample was frozen for the third time. After five days of freeze the vertical cracks were wider but their scheme remained the same. Additional system of horizontal cracks was formed. Therefore, the sample began crumbling and falling from the filtering ring. Clay lamina began to peel off. Vertical

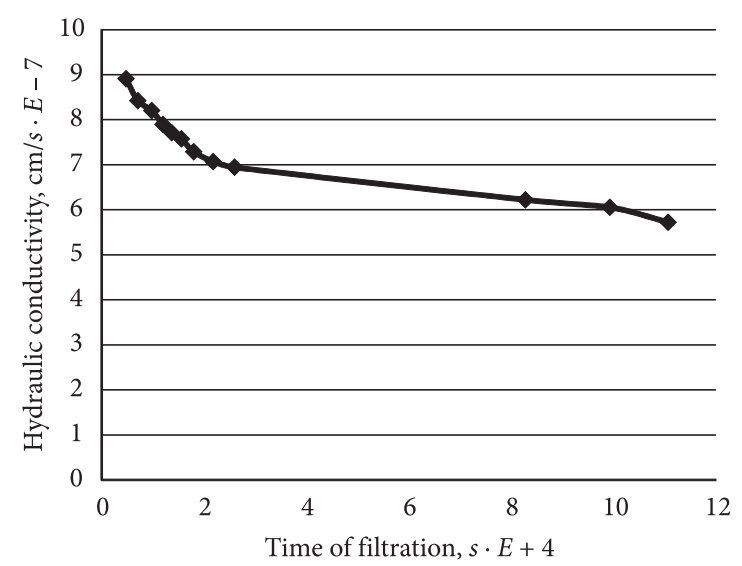

Fig. 7. Variations of hydraulic conductivity during the second filtering stage after the second freeze-thaw cycle

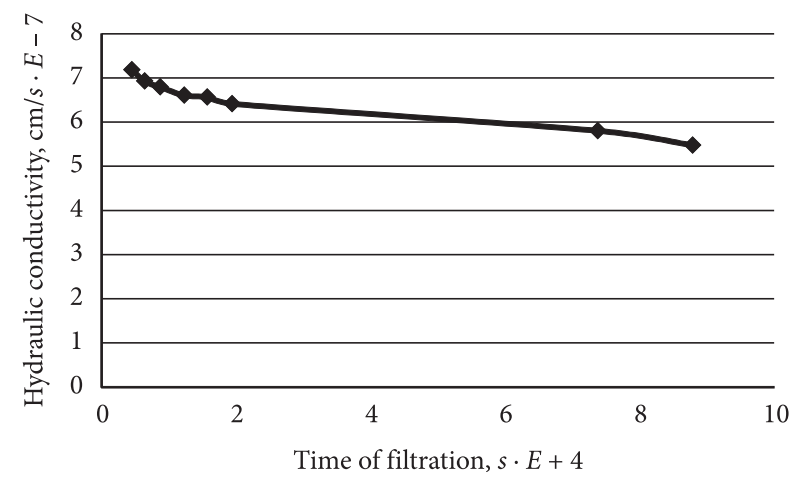

Fig. 8. Variations of hydraulic conductivity in time during the third stage of filtering after the second freeze-thaw cycle

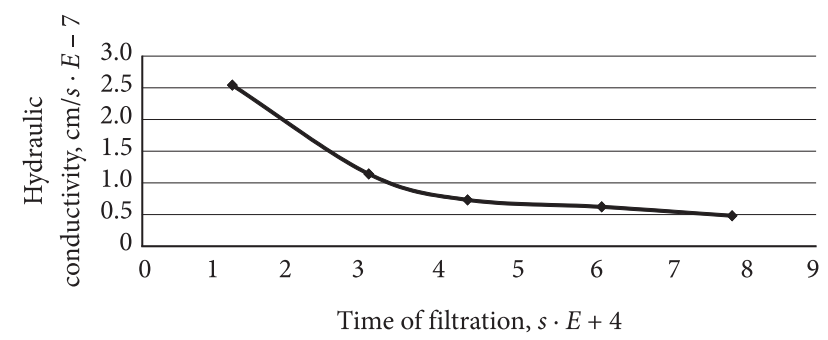

Fig. 9. Time variations in intensity of evaporation directly from the water surface in open-ended hydraulic head piezometer, as recalculated into the hydraulic conductivity corresponding to the evaporation intensity and horizontal cracks joined in the sample over all its height, and the sample crumbled.

Performing the filtration at the laboratory, especially in winter, when the air humidity reached $35-45 \%$, it was necessary to assess the effect of evaporation on the hydraulic head and filtrate debit. Therefore, these characteristics were measured in parallel. The water evaporation volumes and their variations with time, when the water level in piezometer was descending, enabled to assess how this could affect the determined hydraulic conductivity values. The time variations in the hydraulic head and debit values were recalculated into the hydraulic conductivity, if solely the evaporation took place. The results obtained are given in Fig. 9. It is obvious that it would be important, if the conductivity values during the experiments were at 3-4 orders of magnitude lower than the minimum values determined by us.

\section{Conclusions}

1. For the first time in Lithuania experimental research analysing the effect of the number and duration of freeze-thaw cycles on filtrational parameters of clay was performed. Grūda subformation till clay (gIIIgr), taken from the projected Stabatiške waste repository site, was used in these experiments.

2. The generalisation of all the investigation results obtained for this type of clay allows us to formulate several methodological conclusions. The variation in hydraulic conductivity for clay of this type can range from 9.0E-7 to $3.0 \mathrm{E}-$ $8 \mathrm{~cm} / \mathrm{s}$. Its higher values are observed at the start of the filtering. Later, during the experiment, they are decreasing. The repeated experiment with the same sample after some time shows some rise in conductivity values at its start with further possible stabilisation. Therefore, the hydraulic conductivity of clay determined by short-term infiltration studies will be imprecise and unsuitable for long-term prognostication.

3. The effect of clay freeze-thaw cycles on the hydraulic conductivity is not very high. During thawing of the test sample, the hydraulic conductivity ranges from 3.5E-6 to $5.0 \mathrm{E}-7 \mathrm{~cm} / \mathrm{s}$. The fully frozen clay sample is found to contain a newly formed vertical and horizontal crack system that raise the hydraulic conductivity in several times. The colmatation of crack system also takes place during the filtering. The hydraulic conductivity values decreasing with time confirm this, although they remain significantly higher than they were before the freezing. The second freeze-thaw cycle forms very similar system of cracks, but the same cracks are wider than before. The hydraulic conductivity grows further followed by even more slower colmatation causing a rise in clay filtering capacity (permeability).

4. The third freeze-thaw cycle destroyed our sample. Therefore, we could not perform filtering because the crack system formed had broken the structural monolithicness of 
the sample and probably even more improved the filtering capacity (permeability) of clay. As the sample was not fully thawed, it was visually observed how water began percolate via the well seen frozen clay crack system. This filtering cycle was very unstable in time, and only after the sample thawed completely a slow colmatation of cracks began, but the hydraulic conductivity values remained higher than they were before the freezing of the sample.

\section{References}

Al Houri, Z. M.; Barber, M. E.; Yonge, D. R.; Ullman, J. L.; Beutel, M. W. 2009. Impacts of frozen soils on the performance of infiltration treatment facilities, Cold Regions Science and Technology 59(1): 51-57. http://dx.doi.org/10.1016/j.coldregions.2009.06.002

Cassan, M. 2005. Les essais de permeabilite sur site dans la reconnaissance des sols. Paris: Presses des Ponts et Chaussees. $568 \mathrm{p}$.

Dondi, M.; Principi, P.; Raimondo, M.; Zanarini, G. 2003. Water vapour permeability of clay bricks, Construction and Building Materials 17(4): 253-258. http://dx.doi.org/10.1016/S0950-0618(02)00117-4

Ebina, T.; Minja, R. J. A.; Nagase, T.; Onodera, Y.; Chatterjee, A. 2004. Correlation of hydraulic conductivity of clay-sand compacted specimens with clay property, Applied Clay Science 26(1-4): 3-12. http://dx.doi.org/10.1016/j.clay.2003.09.010

Enssle, C. Ph.; Cruchaudet, M.; Croise, J.; Brommundt, J. 2011. Determination of the permeability of the Callovo-Oxfordian clay at the metre to decametre scale, Physics and Chemistry of the Earth 36(17-18): 1669-1678. http://dx.doi.org/10.1016/j.pce.2011.07.031

Gadeikis, S.; Dundulis, K.; Žaržojus, G.; Gadeikyte, S.; Klizas, P.; Urbaitis, D.; Gribulis, D. 2012. Inžinerinių barjerų izoliacinių molio gruntų sluoksnių geotechniniai tyrimai, Mokslas Gamtos Mokslu Fakultete (7): 117-128.

Hamdi, N.; Srasra, E. 2008. Filtration properties of two Tunisian clays suspensions: effect of the nature of clay, Desalination 220(1-3): 194-199. http://dx.doi.org/10.1016/j.desal.2007.02.037

Hayashi, M.; Kamp, G., Schmidt, R. 2003. Focused infiltration of snowmelt water in partially frozen soil under small depressions, Journal of Hydrology 270(3-4): 214-229.

http://dx.doi.org/10.1016/S0022-1694(02)00287-1
Heister, K.; Kleingeld, P. J.; Keijzer, T. J. S.; Loch, J. P. G. 2005. A new laboratory set-up for measurements of electrical, hydraulic, and osmotic fluxes in clays, Engineering Geology 77(3-4): 295-303. http://dx.doi.org/10.1016/j.enggeo.2004.07.020

Jakimavičiūtè-Maselienè, V.; Mažeika, J.; Motiejūnas S. 2012. Radionuclide and heat transport from hypothetical SNF canister in crystalline basement, case of South-Eastern Lithuania, Journal of Environmental Engineering and Landscape Management 20(2): 121-128. http://dx.doi.org/10.3846/16486897.2012.688363

Jobmann, M.; Wilsnack, Th.; Voigt, H.-D. 2010. Investigation of damage-induced permeability of Opalinus clay, International journal of Rock Mechanics and Mining Sciences 47(2): 279285. http://dx.doi.org/10.1016/j.ijrmms.2009.11.009

Jullien, A.; Proust, Ch.; Le Forestier, L.; Baillif, P. 2002. Hydrochemio-mechanical coupling effects on permeability and swelling behaviour of a Ca smectite soaked by $\mathrm{Cu}$ solutions, Applied Clay Science 21(3-4): 143-153. http://dx.doi.org/10.1016/S0169-1317(01)00084-9

Mammar, N.; Rosanne, M.; Prunet-Foch, B.; Thovert, J.-F.; Tevissen, E.; Adler, P. M. 2001. Transport properties of compact clays, Journal of Colloid and Interface Science 240(2): 498508. http://dx.doi.org/10.1006/jcis.2001.7697

McCauley, C. A.; White, D. M.; Lilly, M. R.; Nyman, D. M. 2002. A comparison of hydraulic conductivities, permeabilities and infiltration rates in unfrozen soils, Cold Regions Science and Technology 34(2): 117-125. http://dx.doi.org/10.1016/S0165-232X(01)00064-7

Oradovskaja, A. E. 1983. Hydrogeological importance of water filtration in clays, VSEGINGEO 152(1): 14-19.

Pundytė, N.; Baltrènaitė, E.; Pereira, P. 2011. Anthropogenic effects on heavy metals and macronutrients accumulation in soil and wood of Pinus sylvestris L, Journal of Environmental Engineering and Landscape Management 19(1): 34-43. http://dx.doi.org/10.3846/16486897.2011.557473

Shafiee, A. 2008. Permeability of compacted granule-clay mixtures, Engineering Geology 97(3-4): 199-208. http://dx.doi.org/10.1016/j.enggeo.2008.01.002

Tang, A. M.; Cui, Y.-J.; Richard, G.; Defossez, P. 2011. A study on the air permeability as affected by compression of three French soils, Geoderma 162(1-2): 171-181. http://dx.doi.org/10.1016/j.geoderma.2011.01.019

Petras KLIZAS. Dr, Assoc. Prof. Department of Hydrogeology and Engineering Geology, Vilnius University (VU). Doctor of Science (Natural Science) Vilnius University, Faculty of Natural Sciences, 1994. Master of Science, Neuchatel University (Switzerland), 1992, First degree in Hydrogeology and Geology Moscow State University (Russia) 1978. Publications: author of 4 textbooks, over 45 scientific publications. Research interests: geofiltration, aeration zone, humidity migration, hydraulic conductivity of soils. 